\title{
HUBUNGAN RINITIS ALERGI DAN OBSTRUKTIF SLEEP APNEU DI POLI THT RS UNIVERSITAS MUHAMMADIAYAH MALANG
}

\author{
Indra Setiawan
}

Fakultas Kedokteran, Universitas Muhammadiyah Malang, Jl. Bendungan Sutami 188 A Sumbersari malang, Lowokwaru, Kota Malang, 65145, Indonesia, (0341) 582060

\begin{abstract}
ABSTRAK
Latar belakang: OSA, Obstruktif Sleep Apnea menyebabkan henti nafas dan memicu timbulnya penyakit berbahaya. Rinitis alergi dapat mengganggu kualitas tidur penderita. Penderita rinitis alergi beresiko terkena Obstructive Sleep Apnea karena sumbatan jalan napas napas atas secara berulang sehingga aliran udara ke paru-paru menjadi terhambat. Tujuan: mengetahui insiden Rinitis alergi dengan Obstruktif Sleep Apnea di Poli THT RS UMM Januari- Maret 2013 dan hubungan rhinitis alergi dan obstructive sleep apnea pada pasien Poli THT RS Universitas Muhammadiyah Malang. Hasil penelitian: insidensi OSA pada Responden yang menderita Rinitis Alergi 17,6\%, gejala rinitis alergi yang paling banyak adalah kelompok rinorea dan nasal congestion dengan jumlah responden sebanyak 55 orang (64.71\%), uji Chi Square Rinitis alergi dengan OSA pada pasien Poli THT RS UMM memiliki hubungan yang tidak signifikan (bermakna).
\end{abstract}

Kata kunci : Obstruktif Sleep Apnea

\section{Pendahuluan}

Gangguan napas saat tidur (Obstruktif Sleep Apnea, OSA) adalah sekelompok gangguan yang ditandai dengan kesulitan bernapas saat tidur. OSA diakibatkan karena penyempitan sebagian ataupun seluruhnya dari tenggorokan yang dapat meyebabkan henti napas 10 sampai 20 detik atau beberapa kali dalam satu malam. Gangguan napas saat tidur berhubungan dengan penurunan kualitas hidup dan dapat memicu timbulnya sejumlah penyakit berbahaya seperti meningkatkan resiko dua kali terkena hipertensi, jantung koroner, stroke pada usia muda, disfungsi seksual, bahkan kematian mendadak

Rinitis alergi adalah salah satu penyakit akibat manifestasi reaksi hipersensitivitas tipe I yang diperantarai oleh immunoglobulin E dengan mukosa hidung sebagai sasaran utama Pada rinitis alergi dapat ditemui gejala hidung gatal, bersin-bersin, rinorea dan obstruksi hidung

Rinitis alergi merupakan penyakit yang sangat mengganggu dikarenakan gejalanya dapat berpengaruh terhadap kualitas hidup penderitanya. Penyakit ini dapat mengganggu kualitas tidur penderitanya, selain membutuhkan biaya pengobatan yang relatif mahal,masalah emosi dan gangguan pada social, juga bersifat rekuren, kronis dan progresif. Penyakit ini selain merugikan penderita secara pribadi, namun juga akan merugikan individu sebagai sumber daya manusia

Hubungan antara rinitis alergi dan Obstructive Sleep Apnea sampai saat ini masih belum jelas. Namun dikatakan bahwa dalam penderita rinitis alergi mempunyai resiko yang lebih tinggi terkena Obstructive Sleep Apnea karena pada rinitis alergi terjadi penyumbatan hidung yang meyebabkan sumbatan jalan napas napas atas yang terjadi secara berulang sehingga aliran udara ke paru-paru menjadi terhambat.

\section{Tujuan}

Untuk mengetahui insiden Rinitis alergi dengan Obstruktif Sleep Apnea di Poli THT RS UMM Januari- Maret 2013 dan distribusi usia insiden Rinitis alergi dan Obstructive Sleep Apnea serta hubungan derajat keparahan rhinitis alergi dan obstructive sleep apnea pada pasie Poli THT RS Universitas Muhammadiyah Malang.

\section{Metode Penelitian}

Observasional analitik dengan desain studi cross sectional. Populasi dan Sampel semua Pasien Rhinitis Alergi Poli THT RS UMM periode januari- Maret 2013.

\section{Hasil Penelitian}

Penelitian ini dilakukan terhadap 85 pasien poli THT RS UMM, diperoleh berdasarkan hasil jawaban kuisioner untuk mengetahui Rhinitis Alergi berdasarkan gejala klinis Rinitis alergi (RA), untuk mengetahui responden yang mengalami rintis alergi, serta keadaan yang menimbulkan gangguan tidur dan mendengkur yang diukur dari kuisioner Berlin tentang Obstructive Sleep Apnea (OSA). Kemudian diolah sesuai dengan tujuan penelitian untuk mengetahui adanya hubungan antara rinitis alergi (RA) dengan risiko Obstructive Sleep Apnea (OSA)

Distribusi Frekuensi Responden Berdasarkan Jenis Kelamin

\begin{tabular}{ccc}
\hline Jenis Kelamin & Frekuensi & Persentase $(\%)$ \\
\hline Laki-laki & 29 & 34.1 \\
Perempuan & 56 & 65.9 \\
\hline Total & 85 & 100.0 \\
\hline
\end{tabular}

(Sumber : Data primer yang diolah) 


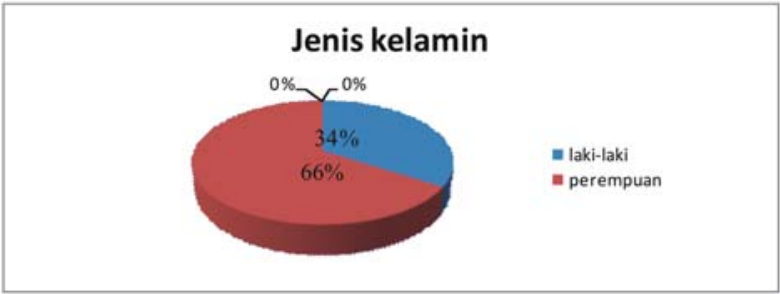

(Sumber: Data primer yang diolah)

Distribusi Frekuensi Jenis Kelamin Responden
Distribusi Responden Berdasarkan Insiden Rinitis Alergi dengan OSA

\begin{tabular}{lcc}
\hline \multicolumn{1}{c}{ OSA } & $\begin{array}{c}\text { Jumlah } \\
\text { Responden }\end{array}$ & Persentase (\%) \\
\hline Positif & 15 & $82,4 \%$ \\
Negatif & 70 & $17,6 \%$ \\
& & $100 \%$ \\
\hline Jumlah & 85 & \\
\hline
\end{tabular}

(sumber: data primer yang diolah)

Berdasarkan tabel diatas insidensi OSA pada Responden yang menderita Rinitis Alergi 17,6\%.

Distribusi Responden Berdasarkan Kelompok Gejala Rinitis Alergi Yang Menyebabkan OSA

\begin{tabular}{|c|c|c|c|c|}
\hline \multirow[t]{2}{*}{ Kelompok } & \multicolumn{2}{|c|}{ OSA } & \multirow{2}{*}{$\begin{array}{c}\text { Jumlah } \\
\text { Responde } \\
\mathrm{n}\end{array}$} & \multirow{2}{*}{$\begin{array}{r}\text { Perset } \\
(\%\end{array}$} \\
\hline & Positif & negatif & & \\
\hline Rinorea & 4 & 1 & 5 & 5.88 \\
\hline Nasal Congestion & 18 & 5 & 23 & 27.0 \\
\hline Rinorea dan Nasal Congestion & 46 & 9 & 55 & 64.7 \\
\hline Tidak Rinorea dan Nasal Congestion & 0 & 2 & 2 & 2.35 \\
\hline Jumlah & & & 85 & $100 . C$ \\
\hline
\end{tabular}

(sumber: data primer yang diolah)

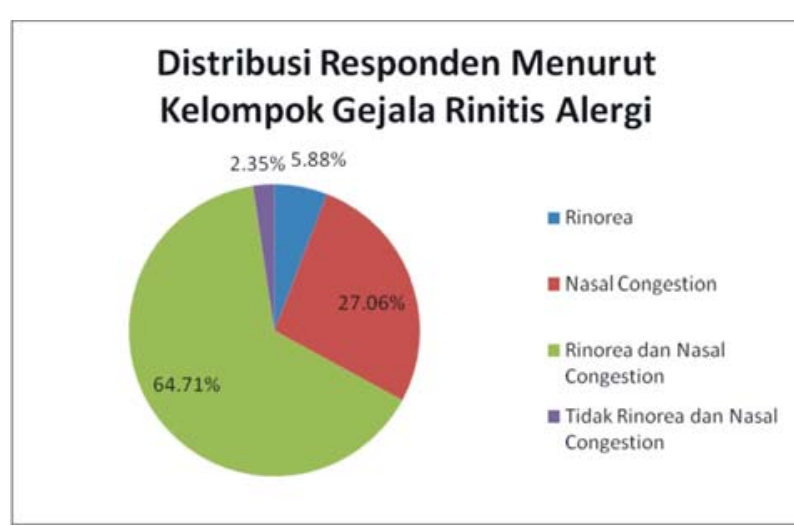

(sumber: Data primer yang diolah)

Berdasarkan data di atas kelompok gejala rinitis alergi yang paling banyak adalah kelompok rinorea dan nasal congestion dengan jumlah responden sebanyak 55 orang $(64.71 \%)$.

Analisis statitistik uji chi-square untuk mengetahui hubungan Rinitis alergi dengan OSA.

\begin{tabular}{llll}
\hline & Value & Df & $\begin{array}{l}\text { Asymp. Sig. } \\
(2 \text {-sided })\end{array}$ \\
\hline $\begin{array}{l}\text { Pearson Chi- } \\
\text { Square }\end{array}$ & 0.775 & 3 & 0.855
\end{tabular}

Dapat disimpulkan bahwa antara Rinitis alergi dengan OSA pada pasien Poli THT RS UMM memiliki hubungan yang tidak signifikan (bermakna).

\section{Pembahasan}

Jenis kelamin perempuan lebih banyak dibandingkan dengan jenis kelamin laki-laki, sesuai dengan penelitian yang dilakukan oleh Pratiwi didapatkan distribusi jenis kelamin laki-laki sebanyak 15 kasus (25\%) dan perempuan sebanyak 45 kasus (75\%), begitu pula penelitian oleh Lumbanraja distribusi jenis kelamin perempuan sebanyak 54 penderita $(87,1 \%)$.

Penderita OSA pada penderita Rinitis Alergi, sebanyak 15 orang $(17,6 \%)$ dari 85 orang yang menderita rinitis alergi, insiden tersebut lebih besar dibandingakan dengan insidensi OSA pada penderita Rinitis Alergi di penelitian sebelumnya yang dilakukan di Trabzon, Turki, yaitu 8,8\% dari 362 orang yang mengalami Rinitis alergi mengalami OSA (Celik, A.S., et al.). Hal ini menunjukkan bahwa insiden OSA pada penderita Rinitis Alergi cukup tinggi.

Berdasarkan kelompok gejala rinorea, hidung buntu, rinorea dan hidung buntu, atau kelompok tanpa rinorea dan hidung buntu. kelompok gejala yang paling banyak terjadi adalah kelompok rinorea dan hidung buntu, yaitu berjumlah 55 orang (46 orang tidak OSA dan 9 orang OSA), yang merupakan kelompok tertinggi penyebab OSA (9 orang). Hal ini menunjukan bahwa rinorea dan hidung buntu merupakan penyebab terbanyak yang terjadinya OSA pada penelitian ini.

Hal tersebut di atas sesuai dengan penelitian sebelumnya yang menjelaskan bahwa terdapat beberapa mekanisme yang bisa menganggu kualitas tidur pada pasien rinitis alergi, namun sumbatan pada hidung dan rinorea merupakan gejala rinitis alergi yang sangat berpengaruh pada gangguan tidur. Akan tetapi gejala rinitis alergi yang lain seperti bersin dan hidung berair juga ikut berperan dalam mekanisme gangguan tidur (Sardana dan Craig). Craig et al juga menyatakan bahwa rinorea/ hidung berair serta obstruksi pada hidung sangatlah berpengaruh pada kualitas tidur dikarenakan gejala tersebut dapat berakibat terjadinya peningkatan resistensi jalan napas yang berakibat tersumbatnya rongga hidung, sehingga dapat dikatakan 
bahwa obstruksi pada hidung merupakan faktor utama terjadinya OSA pada pasien rinitis alergi. Nasal congestion dan rinorea akan mengakibatkan seseorang untuk bernapas melalui mulut (mouth breathing) dan akan mengakibatkan mandibula dan lidah bergerak ke bawah, hal tersebut mengakibatkan penurunan diameter musculus dilator saluran napas atas dan penurunan diameter faring, kedua keadaan tersebut akan mengakibatkan obstrusksi/ terhentinya aliran udara pada pernapasan mulut dan akan mengakibatkan OSA (Chirakalwasan dan Ruxrungtham)

Uji chi-square dengan hasil bahwa Rinitis alergi dan OSA tidak signifikan, seperti juga yang didapatkan Kremer bahwa tidak ada perbedaan yang signifikan saat dilakukan pengukuran menggunakan polysomnografi yang ditemukan dengan membandingkan pasien yang Rinitis dengan yang tidak Rinitis, sehingga Rinitis alergi di kesampingkan sebagai faktor resiko utama terjadi nya OSA.

Berkebalikan dengan teori yang menyatakan bahwa pada Rinitis alergi mukosa pada hidung mengalami edema sehingga dapat meningkatkan resistensi saluran napas atas sebanyak 50\% yang berakibat berkurangnnya aliran udara ke faring (Nunes dan Sole). Selain itu gangguan reflek pada hidung ditambah dengan pernapasan lewat mulut dapat meningkatkan resiko untuk OSA dikarenakan ketika mulut di buka, mandibula bergerak ke bawah yang menyebabkan penggeseran lidah ke arah bawah, dan seterusnnya akan mengakibatkan obstrusi pada pernapasan yang akan menyebabkan terjadinya OSA. Selain itu, juga disebutkan bahwa pada rinitis alegi terdapat peningkatan hitamin, CyslTs, IL-1â, dan IL-4 yang diketahui merupakan mediator dari mekanisme sleep-wake, arousal, dan memori di otak, jika mediator tersebut mengalami peningkatan akan terjadi gangguan tidur dan kualitas tidur yang buruk. Hal tersebut akan memperparah terjadinya OSA (Chirakalwasan and Ruxrungtham).

\section{Kesimpulan}

Penderita OSA pada penderita Rinitis Alergi pada penelitian ini lebih sedikit dibanding yang tidak mengalami OSA. Keluhan Rinorea dan Nasal Congestion yang terbanyak menyebabkan OSA. OSA dan rhinitis alergi pada penelitian ini tidak berhubungan

\section{Penutup}

Keterbatasan pada penelitian ini, yakni diagnosis rinitis alergi pada penelitian ini menggunakan kuesioner ARIA, yang merupakan data subyektif dari responden, sehingga diagnosis Rinitis alergi akan lebih baik lagi bila di ketahui dengan melakukan pemeriksaan fisik dan prict test begitu pula OSA lebih akurat lagi apabila di periksa menggunakan polysomnography. Dan, karena jenis penelitian ini cross-sectional sehingga mungkin kurang representatif untuk menggambarkan hubungan rinitis alergi dengan OSA.

\section{Referensi}

Albarrak M., Banno K., Sabbagh A.,Delaive K, Walld R., Manfreda J., Kryger H.M.,2005, Utilization of Healthcare Resource in Obstructive Sleep Apnea Syndrome: a 5 year Follo-up Study in Men Using CPAP, SLEEP, Vol 28 (9).

American Lung Association, 2010, Obstructive Sleep Apnea or Sleep-Disordered Breathing, State of Lung Disease in Diverse Communities, <http:// www.lungusa.org 1800-LUNG-USA>.

American Thoracic Society, 2009, Obstructive Sleep Apnea in Adult, diakses pada 25 Mei 2014, http:// www.thoracic.org/sections/education/patient-education/patient-information-series/resources/en/sleepstudies.pdf

Angier E., Wallington J.,Scadding G.,Holmes S., Walker S.,2010, Management of allergic and non- allergic rhinitis: a primary care summary of the BSACI guideline, Primary Care Respiratory Journal, Vol 19(3), pp 217 222.

Astuti P, Yunus F, Antariksa B, Ratnawati, 2011, Prevalensi dan Gejala Klinis Obstructive Sleep Apnea (OSA) pada Pasien Asma, J Indon Med Assoc, Vol 61 (7)

Campana L, Eckert J.D, Patel R.S, Malhotra A., 2010, Pathophiology \& Genetics of Obstructive Sleep Apnoea, Indian J Med Res 131, pp 176-187

Deraz E.T.,2010, Immunopathogenesis of allergic Rhinitis,Egypt J Pediatr Allergy Immunol, Vol 8 (1): 3-7.

Epstein J.L, Kristo D, Strollo J.P., Friedman N.,Malhotra A., Susheel P., Patil, Ramar K., Rogers R., et al.,2005, Clinical Guideline for the Evaluation, Management and Long- term Care of Obstructive Sleep Apnea in Adults, Journal of Clinical Sleep Medicine, Vol 5 (3).

Jimenez F.R., RomeroG.P., Martinez LL.J., LM. Teran., 2012, Allergic Rhinitis, Department of Immunogenetic and Allergy, Instutio Nacional de Enfermedades Respiratotorias Mexico, diakses pada 5 September 2014, http://dx.doi.org/10.4172/2155-6121.S5-006.

Lam J.C.M, Sharma S. K, Lam B., 2010, Obstructive sleep apnoea: Definitions, epidemiology \& natural history, Indian J Med Res 131, pp 165-170.

Rimmer J.,Hellgren J.,2012, Allergic Rhinitis and Its Impact on Sleep, Woolcock Institute and University of Sydney, Departement of ENT, Sydney.

Sharma.K.S, Ahluwalia G., 2010, Epidemiology of adult obstructive sleep apnoea syndrome in India, Indian J Med Res 131, pp 171-175

Small P., Kim H.,2011, Allergic Rhinitis, Allergy, Asthma \& Clinical Immunology, diakses pada 26 September 2014, http://www.aacijournal.com/content/7/S1/S3.

Storms W., 2008, Allergic Rhintis- Induced Nasal Congestion : its impact on sleep quality, Primary Care Respiratory Journal, Vol 17 (1).

Strollo J.P, Rogers M.R., 2013, Obstructive Sleep Apnea, The New England Journal Of Medicine, Vol 334 (2).

Plaut M.,Valentine D.M.,2005, Allergic Rhinitis, The New England Journal of Medicine, Vol 352: 1934-44. 